\title{
Cameras in the OR: educational asset or legal liability?
}

n Cite as: CMAJ 2019 September 9;191:E1012-3. doi: 10.1503/cmaj.1095785

Posted on cmajnews.com on August 22, 2019

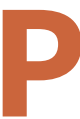

olice have bodycams. Cars have dashcams. Parents have nannycams. Is it time for operating rooms (ORs) to have cameras too?

A Korean lawmaker recently proposed a bill that would have cameras in all the country's ORs, following a petition by a mother whose son died during plastic surgery. Video evidence showed the surgeon had been operating on several patients simultaneously. Last year, a Wisconsin lawmaker put forward a similar bill. Neither bill has yet succeeded. But are cameras in ORs an inevitability?

Of course, modern ORs already have a lot of cameras. Some are fixed to overhead lights to give a bird's-eye view to the surgical team. Some are on devices that surgeons insert through small incisions or orifices to see what they are doing during minimally invasive surgery. Typically, however, video recorded inside the operating theatre is not broadcast beyond it. Nor are records often kept for posterity. Rarely, footage is kept for training purposes.

Why not keep intraoperative video footage? For one thing, storing video raises concerns about patient privacy and confidentiality, says Dr. David Urbach, surgeon-in-chief at Women's College Hospital in Toronto and past-president of the Canadian Association of General Surgeons. Video could contain views of exposed patients. "We at hospitals pay devastating attention to patient confidentiality and privacy," says Urbach.

Then there are questions about whether videos become part of a patient's medical record. According to Ontario's privacy commissioner, they would, and patients could access them.

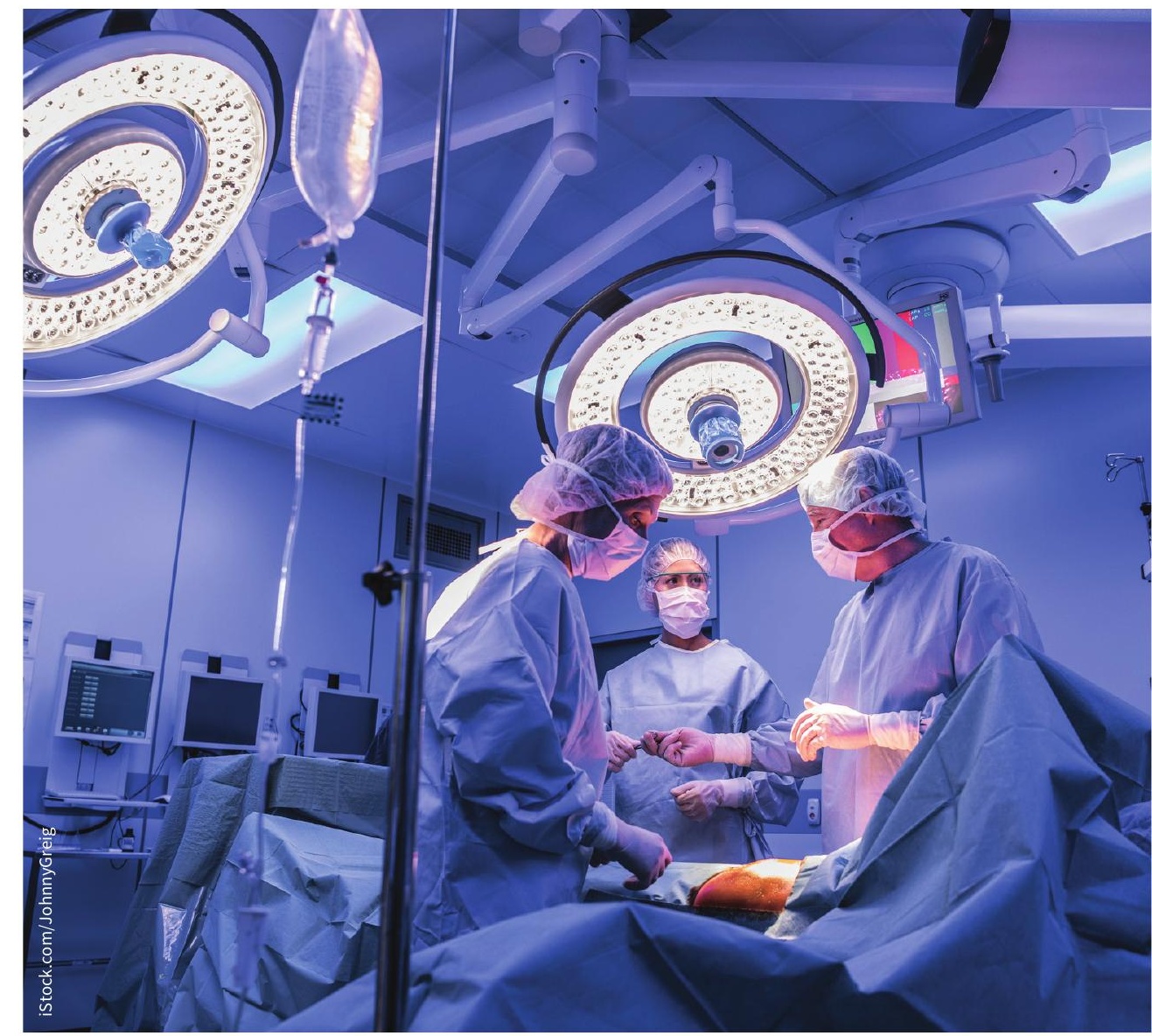

Would surgeons be less candid and proactive if patients had access to video of their procedures?

Almost certainly, if something went wrong and a patient knew a video existed, their lawyer would request it.

Doctors are used to being protected from outside scrutiny, and they should think carefully before forfeiting that, Ellen Epstein Cohen, an American lawyer, said at a Harvard University patient safety conference on this issue almost a decade ago. "We've done a good job legally of making peer review sacrosanct for the most part, versus this transparent idea of everyone can see everything I'm doing, what I'm wearing, how I'm speaking, how I'm holding my instruments, how long this is actually taking me, and so on."

Doctors also worry they might not be as candid and proactive if they knew their actions could be second-guessed after the fact, a concern raised recently by the Korean Intern Resident Association. 
But Dr. Caprice Greenberg, a professor of surgery at the University of Wisconsin at Madison, thinks video is an underutilized tool for surgeons. "Once we finish our training, we really have no formal process for making deliberate changes to improve how we operate," she says.

Her group uses trained surgical coaches to review video one-on-one with a surgeon to improve surgical technique and practice. If you look at any top professionals athletes, musicians, pilots - they have coaches and they're looking for ways to improve, she says. Her program focuses on coaching, but other programs teach by comparing one surgeon's performance to that of others or even by crowdsourcing reviews of surgical performance.
Then there is the OR Black Box, developed by Dr. Teodor Grantcharov, a staff surgeon at St Michael's Hospital in Toronto. It is an OR fitted with cameras that collect images from 360 degrees, and sensors that monitor both the room and the people in it. However, no names, dates or room numbers are captured; faces are blurred; and voices are distorted. "It's totally deidentified by design," he says, making it "impossible" for a patient to track down their own video. This system allows people to learn without the risk of anyone being outed.

Both Grantcharov and Greenberg believe that videos getting into the hands of aggrieved patients is not the potential disaster some have predicted. "I've spo- ken to a lot of lawyers," says Greenberg, "and most say if you have a video, it's much more likely to show that you delivered standard of care than that you didn't." Fetal monitor recordings, she was told, elicited the same type of anxiety at the outset.

But if video is so essential, asks Urbach, why should it be restricted to ORs? Why not have cameras everywhere? Why not record everything all the time? "There's a whole science around the management and prevention of adverse events," he says, "virtually none of which requires video recording or analysis of video recording."

Alison Motluk, Toronto, Ont. 